\title{
Maglev System Design Considerations
}

\author{
Howard T. Coffey \\ Energy Systems Division \\ Argonne National Laboratory
}

\section{DISCLAIMER}

\begin{abstract}
This report was prepared as an account of work sponsored by an agency of the United States Government. Neither the United States Government nor any agency thereof, nor any of their employees, makes any warranty, express or implied, or assumes any legal liability or responsibility for the accuracy, completeness, or usefulness of any information, apparatus, product, or process disclosed, or represents that its use would not infringe privately owned rights. Reference herein to any specific commercial product, process, or service by trade name, trademark, manufacturer, or otherwise does not necessarily constitute or imply its endorsement, recommendation, or favoring by the United States Government or any agency thereof. The views and opinions of authors expressed herein do not necessarily state or reflect those of the United States Government or any agency thereof.
\end{abstract}




\title{
Maglev System Design Considerations
}

\author{
Howard T. Coffey \\ Energy Systems Division \\ Argonne National Laboratory
}

\begin{abstract}
Abstraci
The characteristics of maglev systems being considered for implementation in the United States are speculative. A conference was held at Argonne National Laboratory on November 28-29, 1990, to discuss these characteristics and their implications for the design requirements of operational systems. This paper reviews some of the factors considered during that conference.
\end{abstract}

\section{Introduction}

Although efforts are now being made to develop magnetic levitation technologies in the United States, they have been underway for two decades in Germany and Japan. The systems being developed there have been discussed extensively in the literature and are not repeated here. A National Maglev Initiative, led by the U.S. Department of Transportation and co-chaired by the U.S. Department of Energy and the U.S. Army Corps of Engineers, has been established to evaluate these technologies and to recommend a national maglev strategy. One possible recommendation would be to undertake the development of a new or modified maglev system. If that option is selected, test facilities for developing the technology would be required.

With funding from the State of Illinois, Argonne National Laboratory is studying possible designs of a National Maglev User facility to be used by governmental, industrial, and academic institutions seeking to develop magnetically levitated, high-speed, ground transportation systems. The facility would be available at no cost to the user for research in the public interest and would be available for proprietary research and development if the user pays the "full recovery cost" of the facility. Such a facility is expected to promote the evaluation of maglev concepts by investigators who would not otherwise participate.

A facility for evaluating maglev systems and components must be capable of testing the range of characteristics that operational systems might encounter. To assess the uses to which revenue-producing maglev systems might be applied, over forty experts in transportation and maglev technologies attended a two-day conference at Argonne National Laboratory and discussed their perceptions of these systems. The conference built on System Specifications developed by the Army Corps of Engineers. The conference was loosely structured in brainstorming sessions and cannot be summarized concisely. This summary was assembled from comments made during the conference, but it should not be construed as the consensus of the participants.

\section{Transportation Capabilities and Implicjtions of Maglev Systems}

To be acceptable, a maglev system must provide capabilities in transportation that do not currently exist and cannot be achieved by other means at a lower cost. It will be necessary to determine when, where, how fast, and how many passengers will be transported, what fares they will pay, and how much the system will cost to construct and operate. These questions are currently unanswered and, at best, will be estimated by future studies, some of which are underway. The technology to be used does not need to be known to answer these questions. The answers do, however, affect the technical design of the equipment.

Operational systems can use either the attractive or the repulsive forces between magnetic fields. The former is called the Electromagnetic System (EMS) and the latter the Electrodynamic system (EDS). If desired, speeds of 
250-300 mph are realistically achievable in vehicles or trains using either technology, thereby providing travel times competitive with aircraft over distances up to 500-600 miles. The headway (time or distance between vehicles) will be such that if an obstacle is detected on the guideway or an accident occurs ahead, the vehicle can be stopped with a safe deceleration after a few seconds warning for individuals to prepare for the deceleration. The maximum acceleration expected will be similar to that of an airplane on takeoff, about $0.2 \mathrm{~g}$ 's. More than one stop might be made in major metropolitan areas, but most stations will be spaced from 50 to 200 miles apart, distances that can be traveled in 20-40 minutes. Between Chicago and Detroit, there are six cities with populations of 100,000 or more that could be served by a maglev system.

Since maglev vehicles do not contact the guideway, the primary source of noise will be from the aerodynamic interaction with the vehicle. This noise varies approximately as the sixth power of the velocity. By reducing the speed to about $150 \mathrm{mph}$, the vehicles can be operated virtually noiselessly in metropolitan areas, permitting access to the inner city if desired. And, since they do not depend on traction for levitation or propulsion, operations will be possible in weather conditions that would halt airport operations and slow or stop most other modes of tavel. The same factor allows them to climb steeper grades.

The vehicles will likely be propelled by automated, linear-synchronous motors installed in the guideways, providing precise speed and location control and safe operation of vehicles with headways as short as about one minute and fifteen seconds. If each vehicle carries 150 passengers, 7,200 passengers can be transported per hour in each direction, the equivalent of 18 fully loaded Boeing 747s per hour each way. This capacity might seem modest in terms of commuter traffic needs, but a maglev system will occupy a unique role in transportation, providing a capacity of 2,160,000 passenger-miles of transportation in each direction per hour. By contrast, a single highway lane with vehicles moving at $60 \mathrm{mph}$ accommodates approximately 700 cars per hour, with a peak capacity of about 2,800 passengers per hour, but provides only 168,000 passenger-miles of transportation. The maglev capacity is equivalent to the capacity of almost 13 highway lanes. Since revenues are generally related to the passenger-miles of travel, the system should provide a good revenue potential. (For reference, it was noted that the cust of a four-lane interstate highway in Huntsville, Alabama is about $\$ 7.5$ million per mile total. Renovation of I-80 in New Jersey is running about \$8 -
$\$ 10$ million per mile, and in urban areas the cost for new construction can reach $\$ 50 \mathrm{million} / \mathrm{mile}$ or more. Maglev systems are currently estimated to cost about $\$ 20$ million per mile).

Additional commuter type, but markedly faster, transportation is available within the same system. With reduced speeds in cities, safe headways can be reduced and the throughput can be increased. This increases the capacity to 13,800 passengers/hour in each direction and allows the introduction of 6,600 commuter passengers in separate vehicles on the same guideway. Connecting two vehicles will double the capacity, and the introduction of trains will expand the capacity beyond that which will probably be needed for the foreseeable future. Such highspeed, high-capacity operations will permit airports to be interconnected to alleviate delays associated with weather conditions or to reduce demands for additional capacity. It will also free the airports for more long-range operations.

If service is provided by separate vehicles, arrivals and departures can be scheduled a few minutes apart, ard more service can be provided to intermediate cities without delaying a full train of passengers. Guideways for separate vehicles could be somewhat less massive than those required for trains, and less power would be needed for the motor installed on the guideway. Fewer passengers would congregate at terminals, and the terminals could be smaller. Headways between vehicles would be shorter than for trains with the same capacity and would be determined by the safe stopping time. To achieve the maximum capacity of which the system is capable, high decelerations might be required, and passengers might be required to wear seat belts (as in airplanes). This vehicle mode of operation would interface well with airline operations in which a hundred or so passengers arrive at once. Providing service to intermediate cities will require more switching operations and a somewhat more complex control system.

If trains are used, switching will be less frequent and headways will be greater (for the same system capacity). The guideway would be subjected to different loads and induced vibrations, and more installed power in the motor will be required. Off-F eak loads would entail removing some of the cars from the train, operating a complete train with a reduced load of passengers, or operating with a full load on a still less-frequent schedule. Either system can be implemented.

As an intercity transportation system, passengers can be expected to have luggage that must be moved between transportation modes in a convenient and timely manner. Some workers prefer to have the main node in 
the urban center (with secondary lines to the airports), while others would prefer to locate the main terminals at airports (with access lines to the urban centers). The guideways might be designed for two levels of vehicles, one for urban commuters and one for intercity passengers, $w i s$ transfers being made at the terminals. Vehicles of differing capacities can also be used.

The interface between maglev and other transportation systems is expected to be more than a transfer point, and like canals, seaports and other transportation modes before it, will give new form to the communities it serves. The interface node is expected to become a destination itself. Space must be allowed for transfers to automobiles, personal rapid transit, rental cars, taxis, buses, airplanes, helicopters, ferries, or urban rapid-transit systems. Regional activities, such as recreation, shopping, mediral care etc., will be constructed at these points. The Bay Area Rapid Transit (BART) system is estimated to have resulted in $\$ 20-\$ 30$ billion of commercial construction. As more outlying communities become readily accessible from the metropolitan area, commercial growth and "reverse commuting" will result in these communities.

These systems have a significant capacity to transport high-value, time-sensitive freight and mail, concurrent with passenger transportation or during offpeak periods. This capability could provide a significant source of revenue and a new capability to the U.S. transportation system that have not been thoroughly explored.

Demand for transportation will vary not only between rush hours and off hours, but on weekends and at different seasons as commuters, businessmen, students, and vacationers travel. Operations at night and at off-peak hours during the day provide opportunities for freight transport. Pricing will probibly be modified to account for the different types of passengers carried (as is done in airline pricing schedules).

Land use will be minimal compared with that of some forms of transportation. A 100-foot-wide right-of-way would require only 12 acres of land per mile of two-way guideway. This guideway would be elevated to avoid grade crossings and to avoid the collection of debris on it, permitting the land under or near the guideway to be used for other purposes. Right-of-way requirements differ in different locations. In metropolitan areas, it might be necessary to use abandoned railway rights-of-way or to build the system on the interstate highway system to avoid costly land acquisitions. At the proposed reduced city speeds, such routes are probably practical. In the Long Island,
NY area, the cost of acquiring a new right-of-way is probably prohibitive. Acquisition costs for a new right-ofway for a Chicago-Milwaukee-Minneapolis/St. Paul route, however, is expected to represent only a few percent of the total system cost.

Adequate electrical power is available in highly populated regions of the country, and any effects on the existing power grid are expected to be minimal. The energy required per passenger mile is about one-third that of a commercial jet airplane and can be produced by any electrical energy source, reducing our reliance on petroleum. Electrically powering the system assures that pollutants will be generated only by the power generating plants, where they can be well controlled.

Capital costs of the systems designed by the Japanese and Germans are expected to be high (costs of $\$ 20 \mathrm{million} / \mathrm{mile}$ are cited for the EMS system), but operational and maintenance costs are expected to be low since the energy usage is low, few operating personnel will be required, and the vehicles make no contact with the guideway. A significant opportunity exists to develop a less- expensive guideway in the United States. Questions about the financing and operator(s) of the final system are unresolved.

Essentially, any desired ride quality can be achieved with a maglev system, but the costs increase with improved ride quality, and overemphasizing this factor could make the system too iosily. Ricie quality is a subjective function of many variables, including the accelerations felt by the passengers, the duration of the trip, the temperature and humidity of the vehicles, the noise level, and the amenities provided. All these latter factors can be controlled relatively easily and at much less expense than can the roughness or routing of the guideway, which are major sources of uncomfortable accelerations on the passengers. The design of the vehicle's suspension and damping systems can also provide a smoother ride over rougher guideways. The quality of the ride is increased by banking the guideway to provide coordinated turns in which the forces on the passenger appear as a vertical force only. At high speeds and in sharp turns, the bank angle can become significant, but relatively sharp turns are desired to allow routing the guideway around obstacles or structures or to avoid tunneling. This is an important but imprecisely understood concern that must be resolved to provide an economical design for the system.

Seating and entryways for handicapped personnel will be provided. Platforms at the vehicle floor height are considered adequate for the needs of handicapped persons. If handicapped passengers are provided special seating near doorways, the aisleways will not have to be widened 
beyond that required for other passengers.

Passengers must be shielded from detrimental magnetic fields. This is of concern and under study at this time, and appropriate levels of shielding will result from these studies.

The vehicles must be protected from objects on the guideway or airborne objects, including birds, or designed to suffer no damage from possible contact with them. Screens might be required around the guideway at overpasses to avoid damage from objects falling from the street above. Overall safety requirements will be stringent in this new system and must be assessed in every feature of its design, construction, and operation.

\section{Specific Design Considerations}

In the following sections, some of the specific considerations of the conference are presented.

Accelerations. Accelerations in all directions are a source of forces on the vehicle and guideway and of discomfort to passengers. Normal operational accelerations are expected to be 0.15 to $0.20 \mathrm{~g}$ 's. Unanticipated changes in acceleration (jerk) are bothersome to passengers. Lateral accelerations are more bothersome than positive vertical accelerations (as associated with a dip in the guideway), but repeated accelerations at frequencies around $0.5 \mathrm{~Hz}$-especially those associated with negative accelerations (as associated with topping a hill)-lead to motion sickness. By banking the guideway to achieve a coordinated turn, lateral forces can be avoided, with an insignificant increase in the vertical force. Consequently, the levelness of the track is more important than its curvature. The curvature of the guideway significantly affects the route of the system and the cost of its acquisition.

Aerodynamics-Power and Noise. At sufficiently high speeds, aerodynamic drag, increasing as the square of the speed, is the primary source of drag on (and therefore the major consumer of electrical power for) maglev vehicles. This drag is a function of the shape and frontal area of the vehicle, the vehicle length, and the proximity of the vehicle to the guideway. These loads occur both on the nose and side of the vehicle. Since the side of a vehicle is not streamlined and has a larger surface area than the nose, the side loads can be larger than those on the nose. And, unlike airplanes, these vehicles cannot turn into the wind to take the force in the streamlined direction. The side loads from this source might be greater than centrifugal forces in turns. The importance of these side loads, which must be compensated by the guidance system, can be reduced by using shorter but wider vehicles. Wider vehicles, however, require larger tunnels, possibly precluding the use of existing tunnels. Tunnels present unique aerodynamic problems at these speeds. Aerodynamic loads are also experienced by the guideway and by passing vehicles.

Aerodynamic noise, increasing as the sixth power of speed, will be the major source of noise from the system. As noted earlier, however, speeds will be reduced in or near cities, resulting in major reductions in noise.

Air Travel. In using air travel data to evaluate the demand potential for maglev systems, it is important to note that a major part of the traffic between two terminals can be for through passengers rather than for passengers with their origins and destinations in these terminals. In the Chicago-Detroit corridor there are three times as many passengers passing through as there are passengers having these cities as their origins or destinations. In metropolitan areas, several airports are frequently located in the vicinity of the origin or destination airport, much of which might be diverted to a single maglev line.

Automobile Travel. Automobile traffic is enormous compared with airline traffic, but personal travel will be difficult to capture since drivers ignore the sunk capital cost of their automobile and consider only the variable costs. Some business traffic will be diverted to maglev. Incremental revenue from this source might be realized.

Brakes. Brakes for maglev systems will be design specific, but will probably include aerodynamic brakes as one braking mode. Using friction for braking is very effective if the normal braking mechanisms fail. The system will be under automatic control and on-board personnel will not be able to brake the vehicle.

During high-speed testing of a research vehicle in Pueblo, Colorado, the redundant brakes failed sequentially.

Regenerative braking gen rates electrical power from the kinetir energy of the vehicle. This power is either dissipated in a resistor or fed back into the power system. The latter approach is preferable, but the wave form of the power returned to the system might not be of very high quality, and additional processing might be required 
Bridges/Elevated Structures. Maglev systems are presumed to operate on elevated guideways requiring little earth preparation for their installation. It will be advantageous to prefabricate and standardize prestressed concrete beams and perhaps piers where the weight of the span is such that it can be lifted. Piers are usually cast in place on the foundation and prefabricated beams are installed on them. If the span is long or curved, steel beams are more economical, but the interaction of the magnetic field with the beam must be considered. With the low stresses generated by maglev systems, the governing design parameter is the deflection of the beam, not its strength; consequently, higher strength concretes would be of little use. Other materials might be useful.

The Transrapid system with a small clearance requires more rigid and more precisely installed guideways than the Japanese system with larger clearances. It was estimated that the load-bearing capacity of a bridge could be doubled at a cost that would iut exceed $25 \%$ of the base cost, depending on the foundation, since the major cost of labor for installation will increase only slightly.

Bridges have been a source of malicious vandalism where objects are dropped on passing trains.

Capacity-Operations. Too much capacity in one guideway is undesirable since a disruption of operations would affect transportation in the entire corridor. At some point, it will be desirable to build a second guideway that would avoid this problem while providing transportation services along a different route. The Corps of Engineers System Parameters recommends that crossovers be provided on a two-way system to permit limited operations if one direction of the guideway is blocked for any reason.

Commuters. There is a significant need for commuter transportation in addition to intercity transportation, and many people feel that a maglev system should be designed to handle both loads. On Long Island, a maglev system is seen as offering a substantial benefit to commuters at speeds of only $120 \mathrm{mph}$, providing 45-minute commuting times from Riverside to New York City as compared with a two- and onehalf-hour commute by Long Island Railway. The French TGV (electrified high-speed railway train) provides a 42-minute commute for passengers in a community that was two and one-half hours from Paris by automobile.
Computer Simulations. Computer codes describing the behavior of maglev systems and verified by experiment will be of considerable value in extrapolating the observed behavior in small vehicles to the design of full-scale systems. Testing programs should be geared to developing parameters to validate codes.

Controls - On-Board Personnel. Central control of the system will be required, together with distributed control activities and hierarchial authority. A vehicle entering a sector will activate that sector and assume preeminent control of that and downstream sectors. Messages from this system will be sent back to the central control activity. The train will be made to go at a speed determined by the voltage and frequency of the propulsion system. That speed command will be a function of two levels, one of interblock relationships then a larger integration of multiple blocks.

A cabin attendant will be needed to observe and aid passengers, but being the slowest part of the system, would have no operational function. Some felt that onboard personnel could intercede by relaying the request to the central control system. It might be psychologically necessary to have an employee on board, but their function will be evolutionary like operators on elevators.

The Sao Paulo metro system moves 4.5 million people per day at $50 \mathrm{mph}$ and 30 second headways with no operator. Vancouver operaies trains without operators, and there are two non-passenger-carrying railroads in the United States with no one on board, one in the State of Washington and one in New Mexico.

Costs. The guideway is the most costly portion of the system, and it is divided into the cost of land, foundations and piers, spans, and the propulsion and levitation equipment installed on it. A more flexible guideway would be less expensive. The EMS system is expected to cost from $\$ 15$ to $\$ 20$ million per mile for a complete two-way system, excluding land. A vehicle travelling at 5 miles per minute $(300 \mathrm{mph})$ with a twominute headway has ten miles of guideway associated with it that must be amortized. It seems economical to provide additional technology in the vehicle and increase its cost if this permits the vehicle to travel comfortably and safely over a less-expensive guideway.

The cost of power has been the most rapidly escalating cost of the BART system. Maintenance costs are an important consideration.

The cost of coils in an EDS guideway is expected to be more expensive if they are rigid. It was suggesced 
that these coils be made less rigid and less expensive.

Except for the cost of the Embarcadero station (which was not in the original plan), BART did not attempt to cover costs through the increased value of land. In Los Angeles, special benefit districts were formed around the stations to pay for the station from the tax increment from those districts.

Dynamic Interactions. Dynamic motions of the guideway caused by the passage of a maglev vehicle will differ with single vehicle or train operations. The motion will probably have little effect on the elevated structure but could result in the need for additional suspension control for ride comfort of the vehicle. The interaction between entrained vehicles on the guideway is not simple. Testing a single vehicle and establishing its motions is the first step in assessing this problem.

Earthquakes. The California earthquake of October 1989 caused virtually no damage to the operating Bay Area Rapid Transit (BART) system. Passengers in the transbay tube did not know it had occurred. Overhead structures were constructed on substantial footings and pilings and suffered no damage and required no realignment. Conservative earthquake standards were recommended to be applied nationally. The Japanese high-speed Shinkansen train was said to automatically shut down if an earthquake is sensed. Of more than one hundred earthquakes, only one was suspected to have shifted the track alignment.

Highways/Railroads. In a New York study of maglev, the cost of land was high enough that existing highway rights-of-way were regarded as necessary. The New York thruway right-of-way is typically 200 feet wide and has a maximum grade of $4 \%$. Curves will limit the average speed to $240 \mathrm{mph}$ if a $24^{\circ}$ bank angle is used and $169 \mathrm{mph}$ if a $12^{\circ}$ bank angle is used. The speed would need to be varied frequently to make coordinated turns. The Tri-State High-Speed Rail study found the cost of the right-ofway to be only $2-5 \%$ of the total system cost (rural property at $\$ 8,000$ per acre) and concluded that a new right-of-way should be acquired.

Like maglev, high-speed rail systems would require new rights-of-way for effective utilization, but since trains cannot stop on as steep a bank as some types of maglev systems, the rights-of-way would have to be straighter.
Human Factors. Human factors must be established to determine design criteria. Among these is the assessment of the visual impact of traveling at high speeds and at relatively low heights while rounding curves with the vehicle in a bank and topping hills with the resultant negative $g$ forces. These effects cannot be adequately simulated in existing aircraft simulators. Maglev vehicles will not fly like airplanes in which passengers are seated and belted until the cruising altitude is reached, at which time passengers can move around the cabin until they strap themselves in for the landing. Variations in speed and curves will occur that might be uncomfortable for some passengers. The flicker of objects passing at high speeds has been suggested to be a problem, but it does not in fact appear to be a problem because passengers focus on more distant objects.

The ride quality of the system is not likely to be comparable with a jet plane in smooth air as frequently mentioned. The ride quality can be improved, but the cost of earthwork to do so is a serious consideration. A guideway might be smooth on a local basis, but it will be subject to variations in height caused by settlement, installation tolerances at piers, and temperature variations. Foreign plans are for routes that are straight and level, while in the United States, the focus has been on the use of interstate highway rights-of-way. A system with perturbations will probably have to be constructed and tested to resolve the issue. A closed-loop simulator gives a repetitive pattern and might not be adequate for this purpose. These considerations have a pronounced effect on the design and cost of the system and are clearly topics for further research.

Obstacle Detection. The detection of obstacles on the guideway is an important task, considering the speed of the vehicles and the damage that can be done by relatively small objects. Low-light-level observation of the entire guideway was suggested. Other methods of detection would be desirable.

Power. Most U.S. trains generate power onboard. High-speed trains use catenaries and pantographs to pick up power, while most maglev system concepts use linear-synchronous motors connected directly to the power grid. The motor and power conditioning equipment is carried aboard most trains, while the power conditioning, propulsion, and system control for linear-synchronous motors are located at the wayside.

No difficulty is anticipated in delivering 10-30 MW of power as the vehicle moves through the midwest area, but the system should be connected to a dedicated substation providing parallel $138 \mathrm{kV}$ lines to avoid flicker 
on the line. Sparsely populated regions might have difficulties providing the power.

On-board power must be provided for heating, ventilation and air conditioning, lights, on-board control and communications (and in some cases the power for the suspension and guidance system and its control). This power must be picked up or stored on board.

If sufficient power can be picked up to propel the vehicle or train, the expense of installing a longstator linear-synchronous motor along the entire length of the guideway could be avoided by using a shortstator linear-synchronous or linear induction motor on the vehicle.

It was noted that 1500 amperes of current (at about $5 \mathrm{kV}$ ) has been picked-up at $400 \mathrm{mph}$, but that the pantograph and catenary pick-up system wears out quickly, and the system is accompanied by a great deal of electromagnetic noise. These systems are regarded as not being ready for use since little development has been done on them in the United States in the past 20 years.

Variable-voltage-variable-frequency (VVVF) power systems are needed for the propulsion systems for discrete vehicles. The high-power electronics required are not manufactured in the United States but are available from Germany and possibly Japan. Cycloconverters are limited in their upper frequency capabilities.

The extra power required for heavier vehicles or consists will be more difficult if GTO devices are used for power conversion and conditioning since they are not available in very high-power configurations.

Rights-of-Way. A high-speed maglev rightof-way will be constrained by passenger comfort requirements limiting the vertical and lateral curvature. This leads to complex issues regarding tunneling through or climbing over hills, slowing vehicles to make sharp turns, or purchasing expensive property that might be in the straight line path.

Three considerations arise by allowing the vehicle to bank in turns. First, there is concern that the visual perception of this angle will disturb passengers. Second, the vehicle must be prevented from toppling on its side if it stops in the curve. And third passengers might not be able to safely get out of their seats and exit the vehicle if the angle is too steep. If any of these factors govern the design, the radius of curvature will have to be increased. Railroad beds are typically banked (superelevated) by about $6^{\circ}$ maximum.

Auxiliary uses of the right-of-way for maglev might have major economic benefits and need to be evaluated. The use of optical fibers was mentioned as one supplement that would be compatible with maglev operations. Superconducting power transmission lines were projected to become available within the lifetime of the structure and were recommended for consideration.

High-speed guideways at ground level will need to be fenced. If the maglev system is elevated, the fence can have gates that will permit greater use of the land under and around the guideway, presumably leading to reduced acquisition costs.

If a maglev system is located on a highway rightof-way, an accident on one system might affect the other, so the desirability of having two transportation systems so interrelated needs to be considered.

The price of land in a right-of-way will increase after the decision to acquire it is known. Eminent domain proceedings will be required to acquire the land.

Routes. Argonne National Laboratory studies indicated that maglev routes should connect airports for a variety of reasons, inclúding:

- The airline fare structure is generally higher than that of the railways, and the higher fares could be charged to maglev passengers;

- there is a lack of expansion capability in the airports, which maglev can help alleviate by handling some of the short-haul passengers that would otherwise be carried by the airlines;

- connecting airports permits through passengers to use the maglev system.

The Tri-State High-Speed Rail study elected to study routes from downtown-to-downtown, but the study included links to airports to eliminate long drives and delays to be important.

It was noted that the French TGV has a dedicated rightof-way, except where it enters Paris and Lyon.

Speed. If the system is used for both urban and interurban passengers, the speed of the system would vary widely. BART averages $38 \mathrm{mph}$ with a top speed of 85 
mph. A commuting speed of $150 \mathrm{mph}$ was regarded as too high, but if the vehicles are to be interspersed with interurban vehicles, such speeds might be required. Intercity speeds of $300 \mathrm{mph}$ were usually recommended.

Startle Effect. High-speed vehicles that suddenly come into the view of automobile drivers or that produce a sudden noise can startle the drivers and cause accidents. An example of this is low-flying aircraft crossing highways while landing. This effect is not reduced with time and, in the Paris-Lyon TGV corridor, so many accidents occurred that areas were constructed in which cars could park to watch the trains. By building the guideways $35-40$ feet high and by constructing them so the visibility of and the noise from, the vehicles would be limited, the impact would be lessened.

Stops. Stops in any transportatic. system funded by the public will be dictated by public needs and by economic considerations. Excessive stops reduce the average speed of the system, making it less competitive with other modes of transportation. Too few stops reduce its service to the public. In a practical system, the distance between stations will be greater than in conventional railway systems, but the travel time between terminals can be reduced.

Superconducting Magnets. Superconducting magnets are essential for the performance of the electrodynamic system with high suspension heights, and new technologies for the production of these magnets have been developed as a result of the development of magnets for the superconducting supercollider. The utilization of these magnets in maglev systems must be carefully evaluated to ensure that they are appropriate for use where the safety of the vehicle and passengers is paramount.

High-temperature superconducting mag-nets were not considered in detail since they are speculative. Low-temperature magnets will require liquid helium cooling. Such cooling entails a refrigeration power of about 4 kilowatts for each watt of power dissipated at $4.2 \mathrm{~K}$. A Sterling Cycle refrigerator with relatively higher efficiency would be desirable. Little effort is currently being made to develop these refrigerators in the United States.

Switching/Turning. If separate high-speed vehicles are used, it will be necessary to incorporate switches in the guideway to permit off-line loading and unloading of vehicles. The faster vehicles exit the guideway, the less impact they have on the operation of later vehicles. The Transrapid EMS switches were said to operate in about 15 seconds. Headways are sufficiently great that vehicles can stop if the switch fails.

Vehicles can be switched passively by deploying wheels that lift and guide the vehicle off the guideway onto the siding, or by varying the propulsion to guide the vehicle off the guideway. Early tests of mechanical switches showed t'iat they seldom failed partially, although they frequently failed to operate at all.

The speed at which vehicles should traverse the switch was not agreed upon since the range of systems being considered by different participants varied so widely. The turnaround time for a single vehicle will be less than that for a train unless a circular turnaround track is provided at the end of the route.

Trunk Lines. The TGV system from Paris to Lyon operates 50-100 trains per day, some of which are routed through to Switzerland and others to South France. The Paris-Lyon leg serves as a trunk line for all these trains.

Although airline data is compiled between city pairs, the relevant maglev data combines the ground traffic between city pairs on one trunk line. Boston, Hartford, New York, Philadelphia, and Washington traffic could be on one trunk' with a connecting trunk line to Philadelphia, Pittsburgh, Cleveland, and Chicago. Similarly, in California, six of the top 50 airline city pairs are between the San Francisco metropolitan district and the Los Angeles metropolitan district. One guideway would support all of the maglev travel on a guideway along Interstate 5 .

Restrooms. It was suggested that restrooms would not be required on the vehicle since the time between stops would be relatively short and restrooms would be provided in the terminals. If restrooms are aboard, the alert time before emergency braking commences would be increased, excessively lengthening the headways. This would provide an economic disincentive that might be insurmountable.

Vehicle Size. Size estimates of revenue vehicles varied from 50 to 120 feet in length, with possible articulation of longer vehicles to avoid interference with the guideway. The weight of the TGV was said to be about one metric ton per seat while the Japanese maglev is about 0.2 to 0.3 tons per seat and the Transrapid vehicle about 0.5 tons. The capacity of the vehicle would be about 96-222 passengers per vehicle. The pitch of the 
seats was estimated at 36 inches and the width at 24 inches minimum. The aisles were estimated to be 32 inches wide compared with about 24 inches for airliners. Handicapped passengers would be seated near the doors, avoiding widening the aisles. Two-by two seating was preferred.

\section{Acknowledgments}

This work was performed under Challenge Grant No. 90-82122 from the Illinois Department of Commerce and Community Affairs, Office of Technology Advancement and Development.

Positions and opinions advanced in this paper are those of the author and not necessarily those of SAE. The author is solely responsible for the content of the paper. A process is available by which discussions will be printed with the paper if it is published in SAE Transactions. For permission to publish this paper in full or in part, contact the SAE Publications Division. Persons wishing to submit papers to be considered for presentation or publication through SAE should send the manuscript or a 300 word abstract or a proposed manuscript to: Secretary, Engineering Activity Board, SAE. 

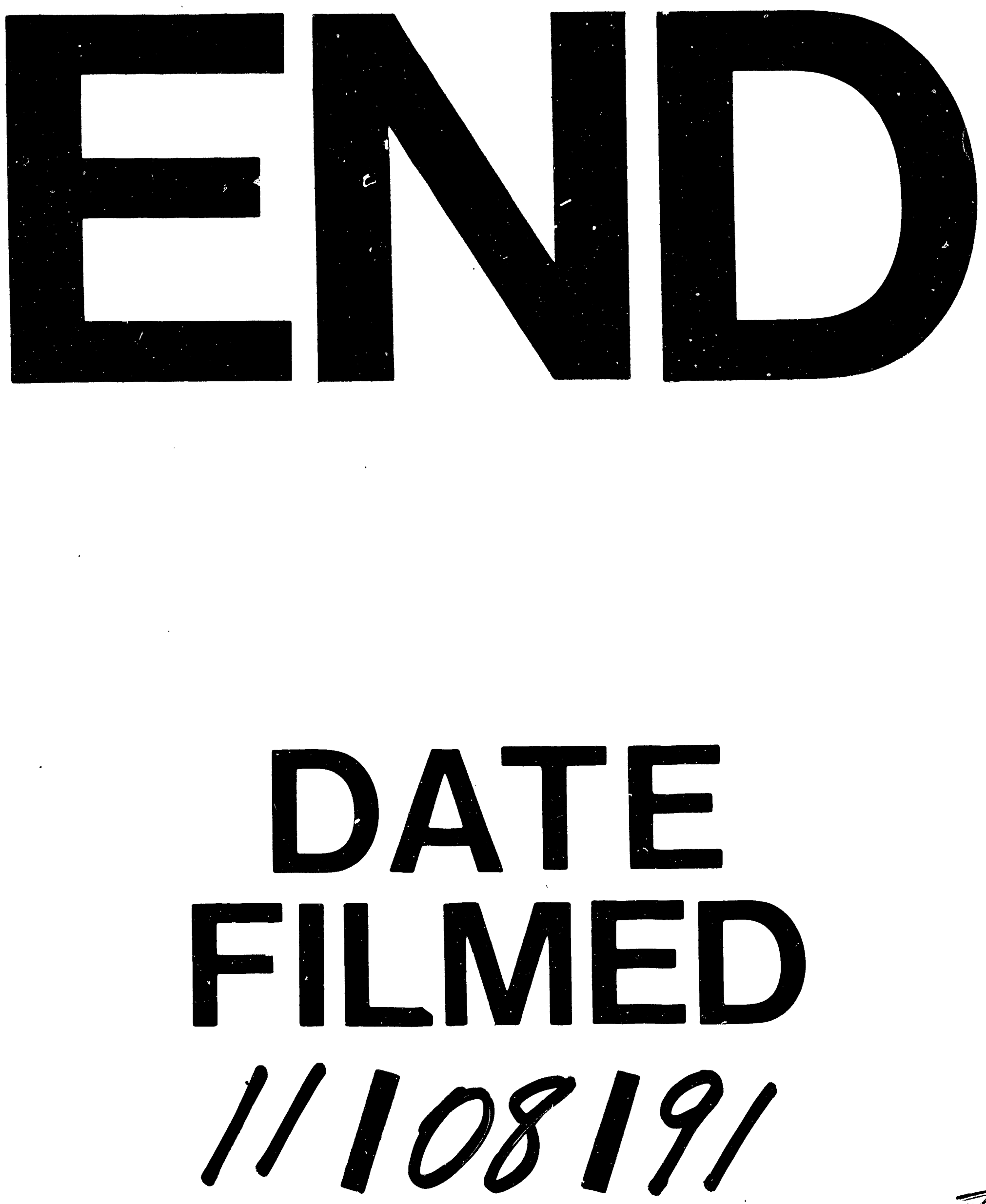

II 
